\title{
Comparative Study on Flexible Link Aerator Using Arduino Programming and Dissolved Oxygen Meter
}

\author{
Fatin Farhana Anuar, Badrul Aisham Md Zain* and Najib Al-Shaibani
}

Advanced Dynamic Control Research Group (ADCARe)' Faculty of Mechanical Engineering \& Manufacturing Universiti Tun Hussein Onn Malaysia (UTHM), 86400 Parit Raja, Batu Pahat, Johor, Malaysia

Received 18 September 2017; accepted 19 April 2018, available online 4 August 2018

\begin{abstract}
Aerator machine is widely used in agricultural sector for maintaining the production and increasing the productivity. The flexible link aerator can be used at tiger prawn pond which is suitable as it only touches the surface of water to generate dissolved oxygen. The flexible link aerator needs improvement on the operation controlling of generating dissolved oxygen to increase the productivity of aquatic lives. Flexible link aerator is one of the machines for producing standard quality water for aquatic lives. Aquatic organism depends on dissolved oxygen for survival. Arduino is the controller unit of the aerator system for controlling the level of dissolved oxygen. To reduce the steady state error the PID is attached together to the aerator system. The model tank is filled with 8 liters, 12 liters and 16 liters of water for analysing the dissolved oxygen. The flexible link aerator is operating on Arduino to get the result based on it before comparing the result of dissolved oxygen meter. The measurement of dissolved oxygen level is based on the dissolved oxygen level set on Arduino. The results from 8 liters, 12 liters and 16 liters of water by using dissolved oxygen meter $22.42 \% \mathrm{O}_{2}, 21.48 \% \mathrm{O}_{2}$ and $21.01 \% \mathrm{O}_{2}$. The results by using Arduino system are $24.75 \% \mathrm{O}_{2}, 23.79 \% \mathrm{O}_{2}$ and $22.34 \% \mathrm{O}_{2}$ at 8 liters, 12 liters and 16 liters of water. The Arduino controller program and the dissolved oxygen meter show its difference in value as the dissolved oxygen meter is considering the temperature.
\end{abstract}

Keywords: Flexible link aerator, Dissolved Oxygen, Arduino and PID controller.

\section{Introduction}

This research is about the control motor operation by using Arduino into the flexible link aerator for controlling the dissolved oxygen in water of prawn pond. Aquatic living requires several properties to surviving. Generally, there need a suitable $\mathrm{pH}$ level, ammonia and dissolved oxygen. The quality of water is important because it can lead to the disease or die. The increasing of $\mathrm{pH}$ level, ammonia and dissolved oxygen can reduce the productivity [1]. The $\mathrm{pH}$ level, ammonia and dissolve oxygen need to maintain suitable to the aquatic living needed.

The aquatic lives might have the problem to obtain suitable dissolved oxygen in water and by using aerator system. It will develop dissolved oxygen automatically. The aerator system only helps to generate the dissolved oxygen then the Arduino is added for controlling the rate of dissolved oxygen in prawn pond. The volume of dissolved oxygen in water for aquatic lives is the parameter that needed to be controlled by Arduino. The flexible link aerator will undergo to fabrication process of improving the motor operation with Arduino. The value of dissolved oxygen in water will be measured for finding the rate of dissolved oxygen for aquatic lives. The experiment processes will start by analyzing the improvement to this new flexible link aerator.

*Corresponding author: aisham@uthm.edu.my

2011 UTHM Publisher. All right reserved.

penerbit.uthm.edu.my/ojs/index.php/ijie
By using Arduino, the flexible link aerator will develop the dissolved oxygen automatically according to the rate of dissolved oxygen for aquatic living. The aerator will undergo the improvement process and experiment to make sure the prototype operates as a flexible link aerator controller of dissolved oxygen in water.

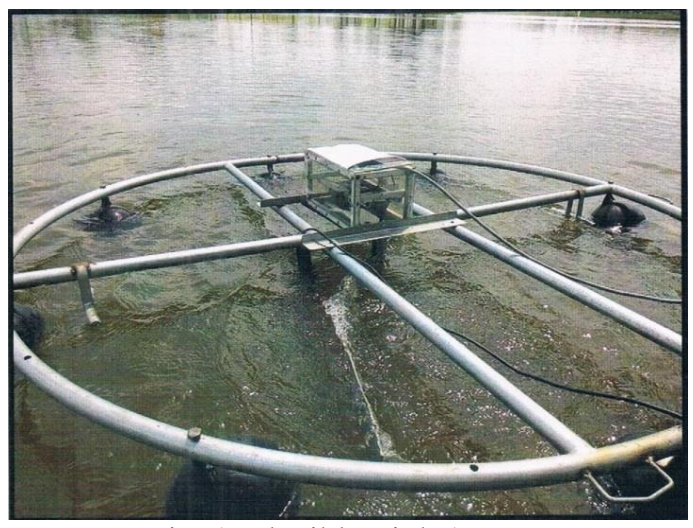

Fig. 1: Flexible Link Aerator

\section{Literature Review}

\subsection{Flexible Link Aerator}

It is the operator that acts as an aerator by using flexible link to generate dissolved oxygen as in Figure 1. After 
that, the flexible link moves from the water surface by the DC motor to generate the bubbles on the water to measure the dissolved oxygen by the developed Arduino system. The flexible link only soaks to the water surface. It is similar to the paddlewheel on producing waves and bubbles for increasing dissolved oxygen in water.

From several types of aerator, it shows that flexible ink aerator produces higher dissolved oxygen in water as shown in Table 1[2].

Table 1: Standard Oxygen Transfer Efficiency of the Basic Type of Aerator [2]

\begin{tabular}{cc}
\hline Type of Aerator & $\begin{array}{c}\text { Average Oxygen Transfer } \\
\text { Efficiency }\left(\mathrm{kgO}_{2} / \mathrm{kWhr}\right)\end{array}$ \\
\hline $\begin{array}{c}\text { Flexible link aerator } \\
\text { with circle holes }\end{array}$ & 2.70 \\
$\begin{array}{c}\text { Flexible link aerator } \\
\text { without circle holes }\end{array}$ & 1.84 \\
Propeller aspirator & 1.58 \\
pump & 1.28 \\
Vertical pump & $1.29-2.75$ \\
Paddlewheel & $0.9-1.9$ \\
Pump sprayer & $0.7-1.2$ \\
Diffused air &
\end{tabular}

\subsection{Dissolved Oxygen}

Aquatic lives depend on dissolved oxygen for survival. Lack of dissolved oxygen will affect their life. They either face death or leave the area to find a better place. Dissolved oxygen concentration is influenced by many aspects such as water turbulence or wave action and the amount of oxygen used by aquatic lives [3].

Water temperature and atmosphere pressure effect the capacity of water to hold dissolved oxygen. It can drop due to weather and dissolved oxygen can increase while raining, and at night. Better quality of water depends largely on the amount of oxygen the water can hold by testing the dissolved oxygen for healthiness of the aquatic lives.

\subsection{Arduino}

The proposed Arduino controller introduced into this project consists of simple implementation control system compared to other controllers [4]. Arduino has input and output process in which it will receive the input from any surrounding situation such as sensor and it will analyze the problem according to the range given then transfer the information to the software and it appears as output for giving the solution for the occurring problem. By referring to the other experiment it also can develop a single phase back to back converter using voltage closed loop feedback with the ability of the Arduino as a low microcontroller to control the gate signal of power [5].

The important key of Arduino is it consists of microcontroller as it has the processor and memory to control any tool by simulating the input and output to produce the desired solutions from problems [6]. It will produce a variety of information such as movement towards robotic machine to operate according to the desired instruction.

Arduino can also be in automated mode from software monitoring to any controller appliances to respond to any signal and related sensor [4]. The Arduino can be communicated with software running on computer for analysis [7].

Machines are usually involved in motor system to produce movement such as in vehicles. Basically, motor is a device for producing energy either electric or mechanical. Motor should be controlled to avoid other system from damage. The motor selection should have high torqued which is 12 volts $4 \mathrm{amp}$ with $3.2 \mathrm{Nm}$ of maximum torque.

\subsection{PID controller}

The PID controller has several important functions and provides feedback and has the ability to eliminate steady state offset through integral action and can anticipate the future of derivative actions [8] [9]. PID controller is an important ingredient of a distributed control system.

Practically, PID controller is created today based on microprocessors. It has the opportunities to provide additional features like automatic tuning gain scheduling and continuous adaption. Auto tuning means that the controller parameters are tuning automatically on demand from an operator or an external signal. The control value is linearly proportional and integral, and there is difference on the error which controls the plant.

By using Zeigler-Nichols tuning method it will determine the PID controller parameter referring to tuning table [9].

Table 2: Tuning of PID controller Parameter according to Zeigler-Nichols Tuning by using step response methods

\begin{tabular}{cccc} 
[9] & \multicolumn{3}{l}{} \\
\hline Controller & $K_{p}$ & $T_{\mathrm{i}}$ & $T_{\mathbb{d}}$ \\
\hline $\mathrm{P}$ & $1 / \alpha$ & & \\
$\mathrm{PI}$ & $0.9 / \alpha$ & $3 L$ & \\
$\mathrm{PID}$ & $1.2 / \alpha$ & $2 L$ & $L / 2$ \\
\hline
\end{tabular}

\section{Methodology}

The methodology is of developing the concept of designing to control the flexible link aerator. Designing the flexible controller link aerator will consist of Arduino system, and PID controller.

\subsection{Concept Generated}

The basic concept for this project is the flexible link aerator operated and control of the dissolved oxygen. For controlling the dissolved oxygen, it consists of Arduino as a controller. For controlling the flexible link by DC motor system, the motor will be attached to Arduino to control the parameter. The information that Arduino receives from sensor will give the instruction to motor for the flexible link aerator as shown in Figure 2. 


\section{Sensor $\Rightarrow$ Arduino $\Rightarrow$ Motor $\Rightarrow$ Flexible Link Aerator}

Fig. 2: The working Principle of the Project

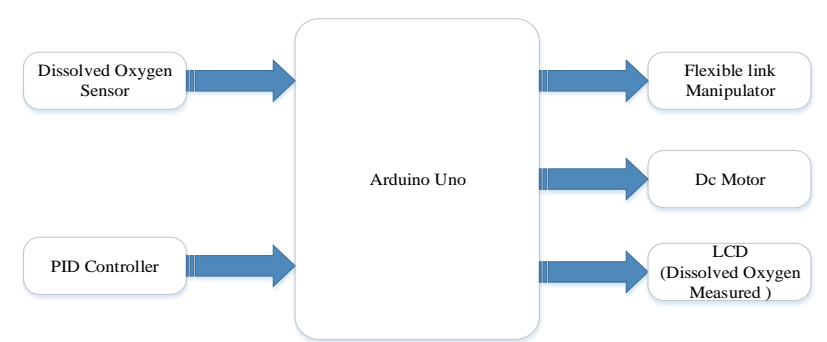

Fig. 3: Block diagram of Arduino System [10].

\subsection{Arduino}

The block diagram of the project and design aspect of independent modules are considered as in Figure 3 [10].

\subsection{The Schematic Diagram of Arduino system}

The schematic diagram of Arduino System is considered as shown in Figure 4.

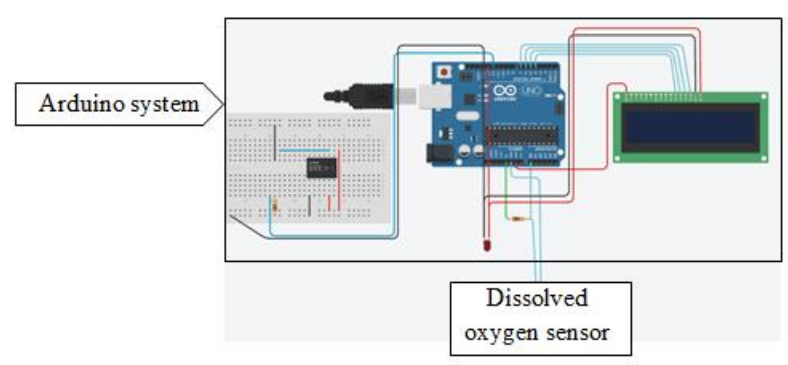

Fig. 4: Schematic Diagram of Arduino System

The schematic diagram above shows the Arduino system arrangement. The Arduino will give the current information about the dissolved oxygen value obtained from sensor. From the dissolved oxygen value, it will contact the motor for adjusting the dissolved oxygen level. The dissolved oxygen value will appear on the LCD according to the parameter measure.

\subsection{The Designing of Arduino Programming}

Arduino will be installing the software for controlling the system. The flow chart of the system is as shown in Figure 5. From Arduino program which has been installed, there will be analysis of the information on sensor detected. The information will be analyzed for controller of the motor operating on adjusting the dissolved oxygen value.

\subsection{Designing the Experiment}

For conducting the experiment, the procedure is as shown in Figure 6. The experiment was set up on model tank with different quantity of water as a parameter to be measured. The model tank was filled with 8 liters, 12 liters and 16 liters of water for measuring the dissolved oxygen to be controlled. The Arduino programming had been uploaded for controlling the dissolved oxygen. The
Arduino was operated based on the level on Arduino which was between $18.0 \% \mathrm{O}_{2}$ and $20.0 \% \mathrm{O}_{2}$ to operate the flexible link aerator.

\subsection{Control Parameter}

The parameter measured was the dissolved oxygen value of controlling the flexible link aerator through motor system. The rate of dissolved oxygen was between $18.0 \% \mathrm{O}_{2}$ and $20.0 \% \mathrm{O}_{2}$. From the previous research, the ideal dissolved oxygen is $18.0 \% \mathrm{O}_{2}$.

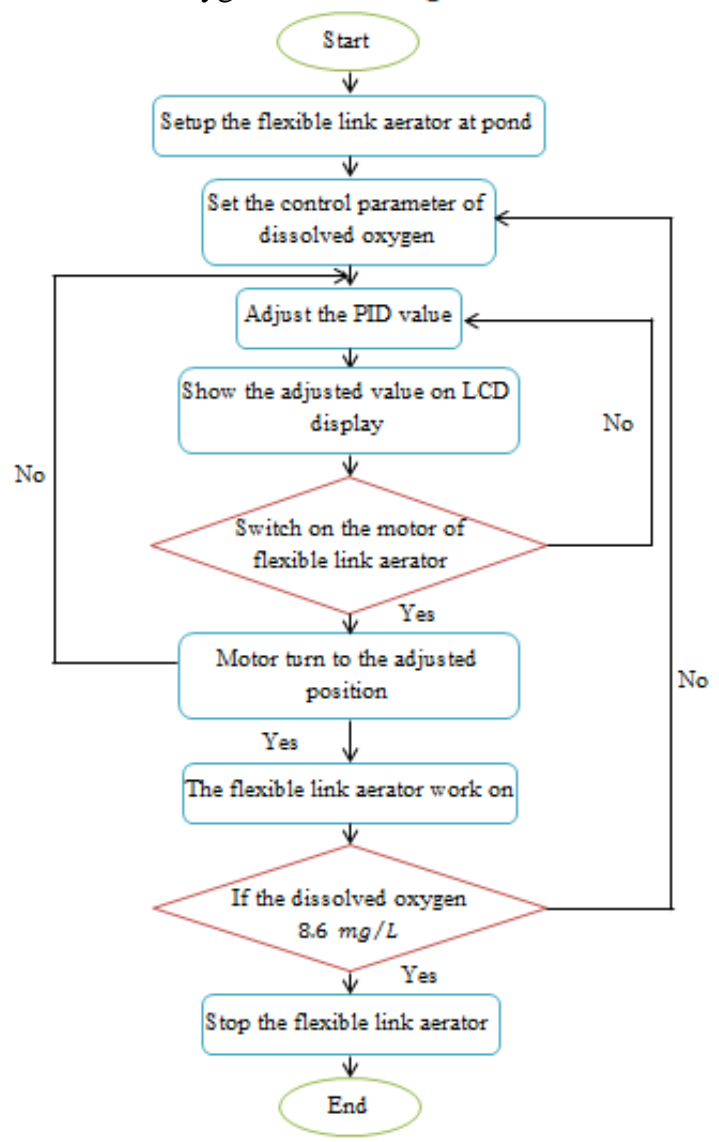

Fig. 5: Flow Chart of the System 


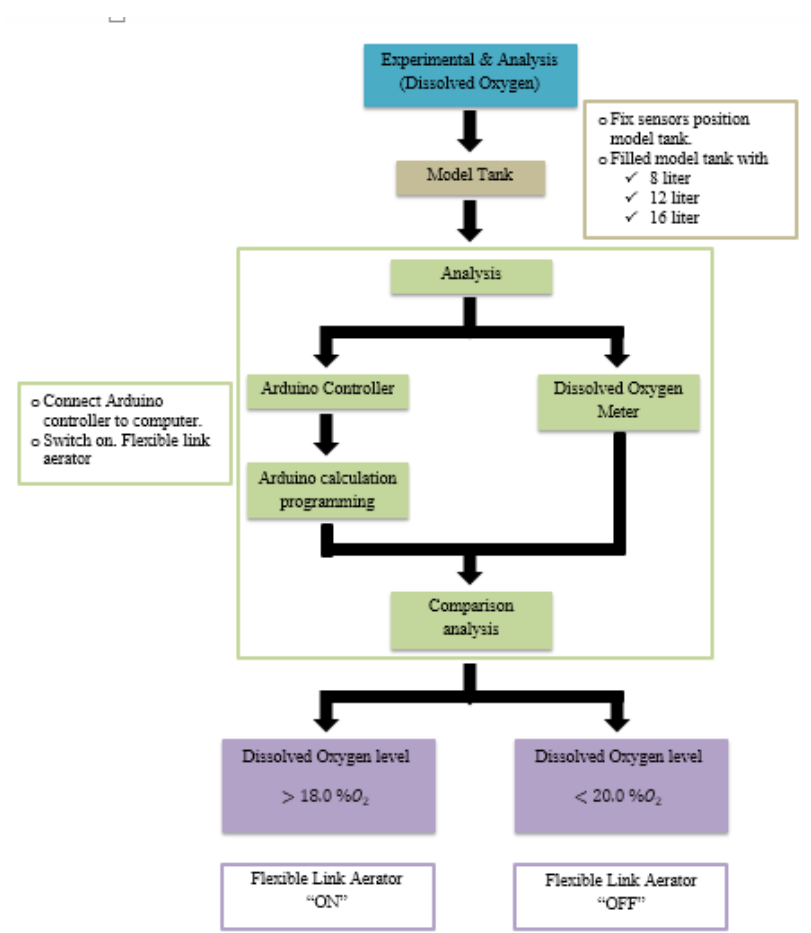

Fig. 6: Experimental Procedure

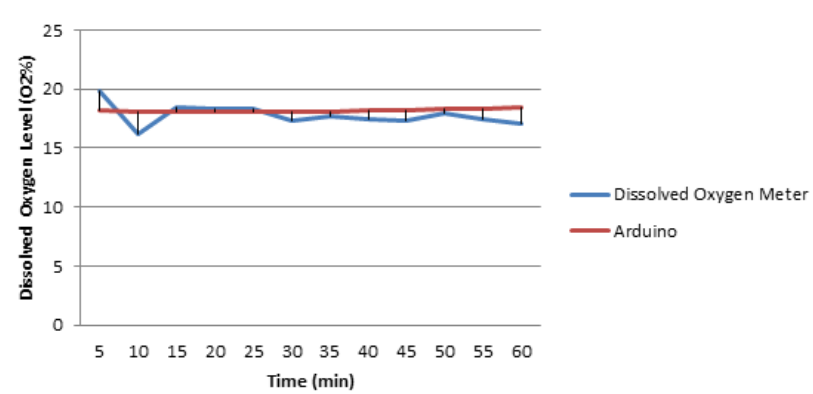

Fig. 7: Comparison Dissolved Oxygen Meter and Arduino against Time.

The average dissolved oxygen level by using Arduino programming is $18.18 \% \mathrm{O}_{2}$ and $17.77 \% \mathrm{O}_{2}$ is the value of average dissolved oxygen obtained from Dissolved Oxygen Meter.

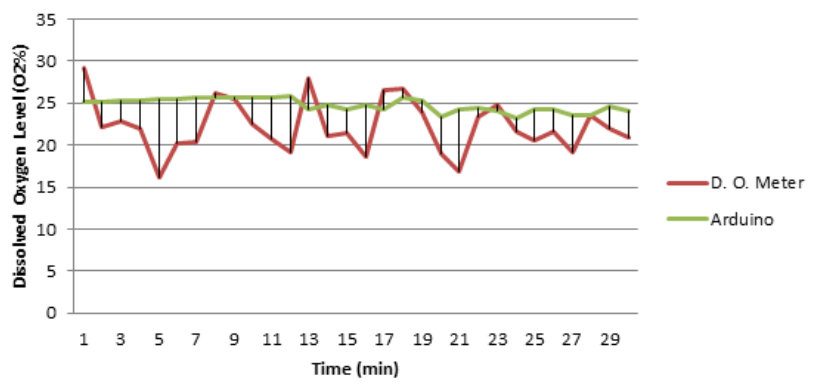

Fig. 8: Comparison between Dissolved Oxygen Meter and Arduino against Time for 8 liters of water.

\subsection{Analysis of Experiment}

The experiment was conducted by using different amounts of water through the experiment. 8 liters, 12 liters and 16 liters. The model tank was filled with water with initial dissolved oxygen level of $17.8 \% \mathrm{O}_{2}$ and the initial temperature of $28.1^{\circ} \mathrm{C}$. The desired range of dissolved oxygen is between $18.0 \% \mathrm{O}_{2}$ and $20.0 \% \mathrm{O}_{2}$.

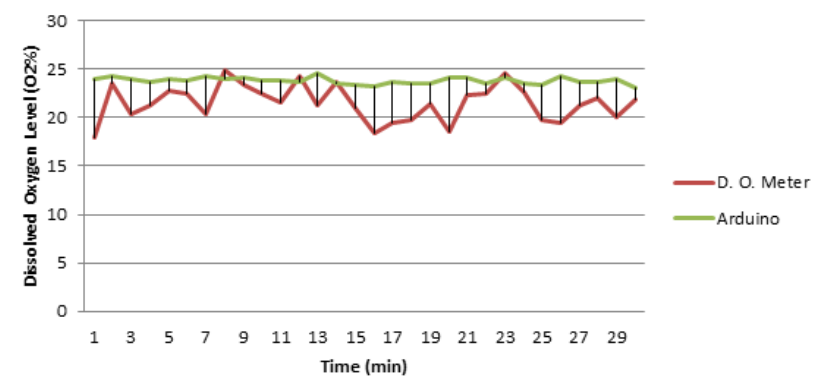

Fig. 9: Graph of comparison between Dissolved Oxygen Meter and Arduino against Time for 12 liters of water.

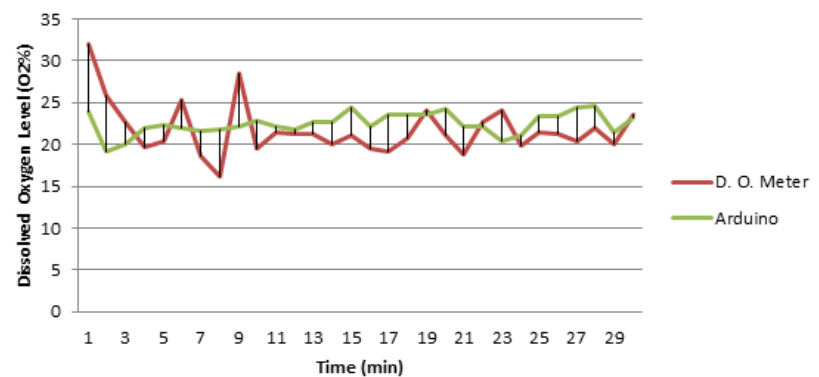

Fig. 10: Comparison between Dissolved Oxygen Meter and Arduino against Time for 16 liters of water.

Based on the experiment of comparing the value of dissolved oxygen between Arduino and Dissolved Oxygen Meter without operating the motor of flexible link shows that there is difference which is $18.18 \% \mathrm{O}_{2}$ and $17.77 \% \mathrm{O}_{2}$ because different types of sensor were used in Arduino

From the experiment, it can be seen that for 8 liter of water, the dissolved oxygen value is higher than 12 liter and 16 liter of water. The value of dissolved oxygen for 8 liter of water based on Dissolved Oxygen Meter that gives the average value within 30 minutes of the experiment is $22.42 \% \mathrm{O}_{2}$ and the dissolved oxygen based on Arduino is $24.75 \% \mathrm{O}_{2}$. For 12 liter and 16 liter of water, they show an average value of dissolved oxygen by using Dissolved Oxygen Meter of $21.48 \% \mathrm{O}_{2}$ and $21.01 \% \mathrm{O}_{2}$ respectively which is lower than the 8 liters of water dissolved oxygen value. Based on the Arduino programming, the average value of dissolved oxygen for 12 liters of water is $23.79 \% \mathrm{O}_{2}$ and $22.34 \% \mathrm{O}_{2}$ for 16 liter of water show that it is lower compared to the 8 liter of water dissolved oxygen value.

The initial readings of dissolved oxygen for 8 liters of water is higher than 12 liter of water which are $29.1 \% \mathrm{O}_{2}$ and $17.9 \% \mathrm{O}_{2}$ respectively. While for 16 liters of water, the reading got lower dissolved oxygen due to the higher the amount of water required in higher dissolved oxygen. For PID controller system, the set up value on Arduino programming is automatic. The PID set point will adjust automatically based on the 
formula set in Arduino programming. From the experiment, it gives almost the same reading of dissolved oxygen for each volume of water because the PID controller programming had been set on Arduino.

\section{Conclusion}

The conclusion is two objectives of this research had been achieved. The experiment had been conducted to fulfil the objective requirement. The concept of controlling the dissolved oxygen level by using Arduino programming is to maintain the quality of water for aquatic lives such as tiger prawns.

The first objective to generate dissolved oxygen of flexible link aerator by using Arduino is achieved. Based on the experiment conducted, the value of dissolved oxygen for different volume of water shows that the higher the volume of water the lower the dissolved oxygen value. The experiment was conducted at the same area of water but with difference in the volume of water. The higher initial reading is at 8 liters of water which is $22.42 \% \mathrm{O}_{2}$ compared to 16 liters of water which is $21.01 \% \mathrm{O}_{2}$ It means that the flexible link needs to adjust the dissolved oxygen value if the volume increases.

The second objective is to implement the PID controller of controlling the flexible link aerator. The PID controller is used in Arduino programming to control the motor operation. PID controller it already on Arduino programming and connected with potentiometer for adjusting. The Arduino programming will adjust the value based on the potentiometer value set up. The value of set point, input, and output value for PID controller are set on the Arduino programming to operate the programming according to the formula.

The recommendation is replacing the Conductivity water sensor with dissolved oxygen probe, which can give more accurate value of dissolved oxygen. The Electrical Conductivity Water Sensor for dissolved oxygen could also be replaced with the Analog Electrical Conductivity Meter with temperature compensation. The analog electrical conductivity meter can give out more accurate reading with temperature compensation. The Radio Frequency (RF) system for the operation of flexible link aerator could also be operated.

\section{Acknowledgement}

The authors would like to acknowledge the financial support received from the Research Management Centre (RMC) Universiti Tun Hussein Onn Malaysia (UTHM) under the Tier 1 Research Grant Scheme (Code H242).

\section{References}

[1] Wahid, H. Mohd Noor, A. F. Burhanuddin, D. H. (2017). Design of an Automated Hybrid System for Aquaculture and Agriculture Process and Its Performance Analysis. International Journal of Integrated Engineering. Vol.9 No.4 p. 49-56.

[2] Ayub. M., (2015). Design of Flexible Link Aerator System to Generate Dissolved Oxygen in Prawn Pond. Universiti Tun Hussein Onn
Malaysia: Tesis Sarjana Muda.

[3] Water Action Volunteers. (2006). Dissolved Oxygen Aquatic Life Depends on It. Volunteer Monitoring Factsheet Series, pp 1-4.

[4] Bader, M.O., Al-thobaiti, Iman, I.M., Abosolaiman, Mahdi, H. M., Alzahrani, Sami, H., A. Almalki, Mohamed, and S. Soliman., Design and Implementation of a Reliable Wireless Real-Time Home Automation System Based on Arduino Uno Single-Borad Micrcontroller. International Journal of Control, Automation and System, Volume 3, (2014), pp 11-15.

[5] Zulkifi, S. A. Zakaria, M. Z. (2016), Development of Single Phase Back to Back Converter with Closed Loop Voltage Feedback Controlled by Arduino Microcontroller. International Journal of Integrated Engineering. Vol.8 No.1, pg1-4.

[6] Smith, A. G. (2011), Introduction to Arduino, pg1.

[7] Krishnamurthi, K., Thapa, S., Kothari, L., and Prakash, A., Arduino Based Weather Monitoring System. International Journal of Engineering Research and General Science, Volume 3, (2015), pp 452-458.

[8] Latha, D. V. P., and Devabhaktuni, S. Soil Moisture and Temperature sensor based intelligent irrigation water pump controlling system using Arduino. American Journal of Sustainable Cities and Society, Volume 1, (2014), pp 175-183.

[9] Sarhan, H., A Software-Based Gain Scheduling of PID Controller. International Journal of Instrumentation and Control System, Volume 4, (2014), pp 1-10.

[10] Bansal, R. A.Patra and Bhuria, V., Design of PID Controller for Plant Cintrol and Comparison with Z-N PID Controller. International Journal of Emerging Technology and Advanced Engineering, Volume 2, (2012), pp 312-215. 